\title{
Welfare with IoT Technology Using Fuzzy Logic
}

Vojtěch Novák, Jan Pavlík, Michal Stočes, Jiří Vaněk, Jan Jarolímek

Department of Information Technologies, Faculty of Economics and Management, Czech University of Life Sciences in Prague, Czech Republic

\begin{abstract}
The article describes the concept of deploying IoT technologies within the environment of agrarian operations using a system approach with a focus on fuzzy logic. In addition to the introductory acquaintance with IoT and fuzzy theory, the paper focuses on specific possibilities of applying the fuzzy approach, especially in the case of animal husbandry. The main benefit for this field is the fulfillment of welfare principles and the achievement of economic savings based on optimization. The article also showcases a practical implementation of a demonstrative solution in the JavaScript programming language using data from IoT sensors.
\end{abstract}

\section{Keywords}

IoT, Fuzzy Logic, Welfare, Networks, Precision Agriculture, Smart Agriculture, JavaScript.

Novák, V., Pavlík, J., Stočes, M., Vaněk, J. and Jarolímek, J. (2020) "Welfare with IoT Technology Using Fuzzy Logic", AGRIS on-line Papers in Economics and Informatics, Vol. 12, No. 2, pp. 111-118. ISSN 1804-1930. DOI 10.7160/aol.2020.120210.

\section{Introduction}

Technological solutions, such as the modern IoT (Internet of Things), can solve problems or bring about the optimization of existing processes, but only if they can naturally interact with the environment in which they are deployed.

This approach is best suited for implementations of continuous, i.e. analog systems, which can respond to change immediately in almost an unlimited number of levels. However, to be able to apply the available numerical methods to these systems, digitization is necessary. This allows to express reality using a discrete approach with a limited number of levels. Therefore it is necessary to focus on those principles of IoT that are based on the discrete approach, for example that the measurement takes place only a few times over a defined period (sampling) and the values are quantized to predefined levels (Rymarczyk, 2020).

IoT issues are more increasingly important and experience dramatic development in many areas. Such development brings many new technological innovations as well as generated new problems. Vast quantities of IoT devices in use or still in development need to be categorized based on their usage, type, internet connection, place of implementation etc. One of the important places of usage is agrarian sector and countryside in general. It belongs to one of the more "traditional" areas of IoT implementation, but there is still a lot of room for further development (Stočes et al., 2016).

Fuzzy logic and IoT technology were also presented as a strategy to develop an intelligent irrigation approach that fosters water conservation and better irrigation management in areas with high levels of water stress. The developed fuzzy controller, based on Mamdani fuzzification using trapezoidal and triangular membership functions, efficiently set the time and duration of irrigation for a given crop. The use of fuzzy control helped maintaining the moisture above a pre-set value with smooth variations preventing frequent system's run-off and preserving water and energy. To monitor system in real time, a wide-range ZigBee based wireless network was also used. The system is easy to implement, and economically justifiable (Alomar and Alazzam, 2019).

The combination of IoT and fuzzy logic is also being successfully used is various non-agriculture applications. For instance, the fuzzy logic model was used to control the intensity of light emitted by lighting. Using this approach, it is possible to enlighten the environment according to the conditions and not waste energy by producing excessive lighting (Altun and Dörterler and Doğru, 2018). Another possible 
application of this approach is in fashion retail as described by (Chan, Lau and Fan, 2018).

\section{Materials and methods}

Fuzzy logic is fundamentally built upon the concept of fuzzy sets (Rezaee and Kadkhodaie-Ilkhchi and Alizadeh, 2008). Even though the gradual evolution of the expression of uncertainty using probability theory was challenged first in 1937 by Max Black (Ross, 2004), Lofi Zadeh at the University of California initiated research into fuzzy logic approach in 1965. Since then, fuzzy logic has fully come of age. Its foundations have become firmer, its applications have grown in number and variety, and its influence within the basic sciences, especially in mathematical and physical sciences, has become more visible and more substantive. Yet, there are two questions, that are still frequently raised: a) what is fuzzy logic and b) what can be done with fuzzy logic that cannot be done equally well with other methodologies, e.g., predicate logic, probability theory, neural network theory, Bayesian networks, and classical control? One suggested answer is that the main contribution of fuzzy logic is a methodology for computing with words, as no other methodology serves this specific purpose. A fuller exposition of the methodology of computing with words (CW) will appear in a forthcoming paper. Needless to say, there is more to fuzzy logic than a methodology for CW (Zadeh, 1996).

In general, the fuzzy inference system consists of four modules, the first one is the fuzzification module that transforms the system inputs which are crisp numbers, into fuzzy sets. The second module is called knowledge base, it stores the IF-THEN rules, the rules normally specified by experts. The third module is called the inference engine, it simulates human reasoning process by making fuzzy inference on the inputs and IF-THEN rules. The fourth and last one is called defuzzification module that uses inference engine to transforms the fuzzy set into a crisp value (Fayaz and Kim, 2017).

The following Figure 1 shows the above process where the second and third mudules are merged into a fuzzy inference step.

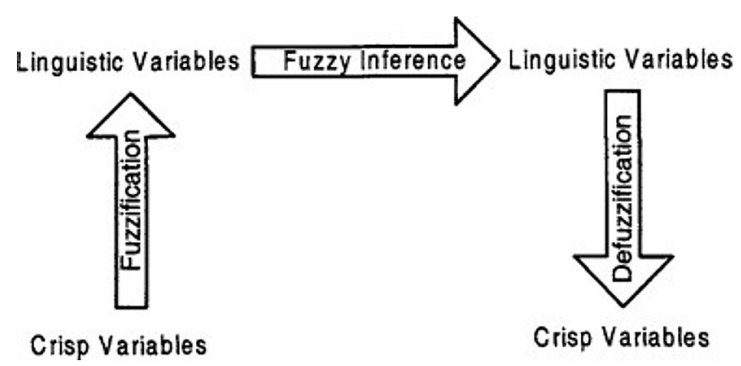

Source: Wang, 2001

Figure 1: Fuzzy logic concept.

\section{Fuzzification}

Fuzzification is a step to determine the degree to which an input data belongs to each of the appropriate fuzzy sets via the membership functions (Xu, 2010). In fuzzy logic, a fuzzy inference system is used as a procedure, in which the input is converted in to fuzzy sets with the help of membership functions like for instance: triangular, trapezoidal, gaussian, or sigmoidal (Patel and Champaneria, 2017) (see Figure 2).

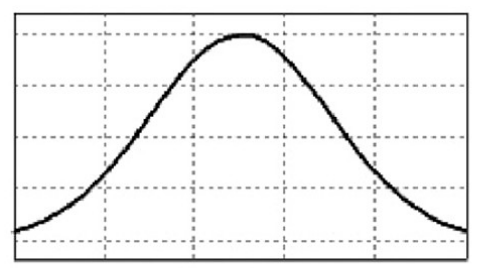

Gaussian

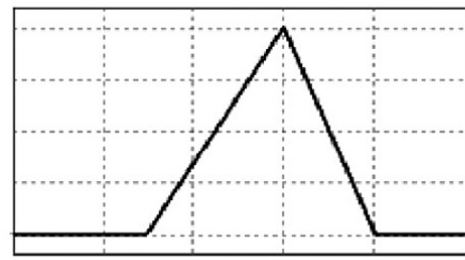

Triangular

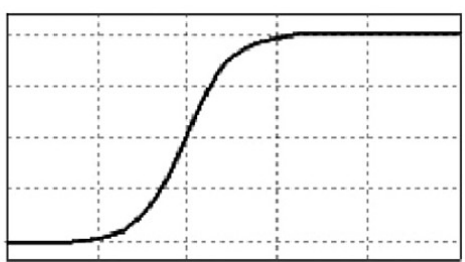

Sigmoid

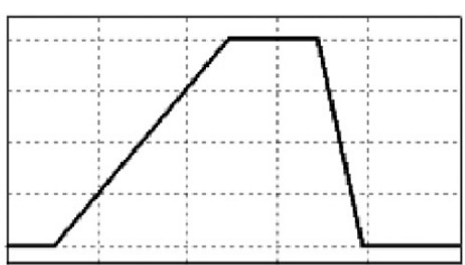

Trapezoidal

Source: Rezaee and Kadkhodaie-Ilkhchi and Alizadeh, 2008

Figure 2: Four types of fuzzy membership functions: Gaussian, sigmoid, triangular and trapezoidal. 


\section{Membership functions}

Definition: a membership function for a fuzzy set $\mathrm{A}$ on the universe of discourse $\mathrm{X}$ is defined as $\mu \mathrm{A}: \mathrm{X} \rightarrow[0,1]$, where each element of $\mathrm{X}$ is mapped to a value between 0 and 1 . This value, called membership value or degree of membership, quantifies the grade of membership of the element in $X$ to the fuzzy set A. Membership functions allow us to graphically represent a fuzzy set. The $\mathrm{x}$ axis represents the universe of discourse, whereas the $y$ axis represents the degrees of membership in the $[0,1]$ interval (Alonso, [no date]).

Below is the list of membership functions we will use in our experiment:

Triangular function: defined by a lower limit a, an upper limit $\mathbf{b}$, and a value $\mathbf{m}$, where

$\mathbf{a}<\mathbf{m}<\mathbf{b}$. It is described in formula (1), and shown in Figure 3 (Alonso, [no date]).

$\mu_{A}(X)=\left\{\begin{aligned} \frac{x-a}{m-a}, & x \leq a \\ \text { (1) } & a<x \leq m \\ \frac{b-x}{b-m}, & m<x<b \\ 0, & x \geq b\end{aligned}\right.$

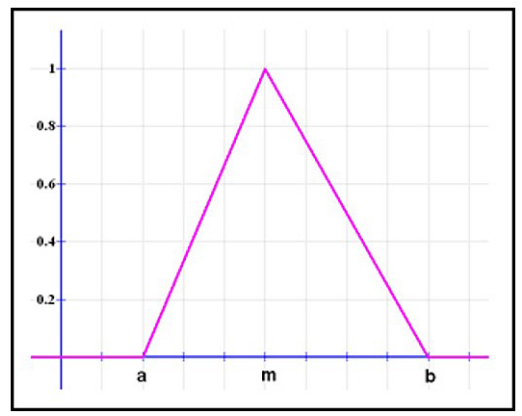

Source: Alonso, [no date]

Figure 3: Triangular function.

Trapezoidal function: defined by a lower limit a, an upper limit d, a lower support limit b, and an upper support limit $\mathbf{c}$, where $\mathbf{a}<\mathbf{b}<\mathbf{c}<\mathbf{d}$. $\mathrm{t}$ is described in formula (2), and shown in Figure 4 (Alonso, [no date]).

$\mu_{A}(X)=\left\{\begin{aligned} 0, & x>d \\ \frac{d-x}{d-c}, & c \leq x \leq d \\ 1, & x<c\end{aligned}\right.$

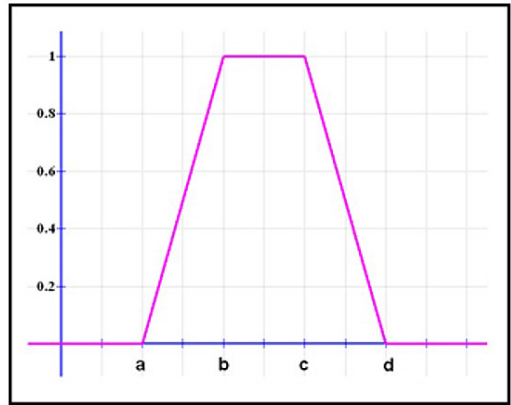

Source: Alonso, [no date]

Figure 4: Trapezoidal function.

Grade function: with parameters $\mathbf{a}=\mathbf{b}=-\infty$. It is described in formula (3), and shown in Figure 5 (Alonso, [no date]).

$\mu_{A}(X)=\left\{\begin{aligned} 0, & x<a \\ \frac{x-a}{b-a}, & a \leq x \leq b \\ 1, & x>b\end{aligned}\right.$

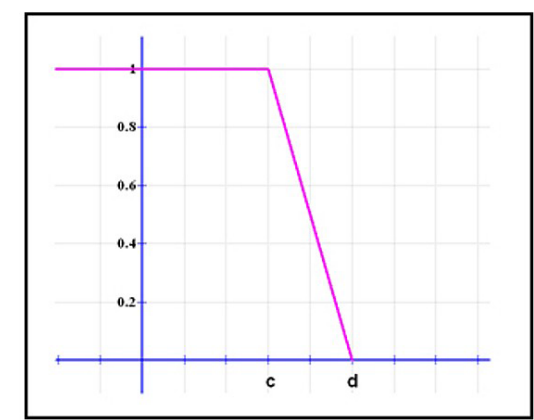

Source: Alonso, [no date]

Figure 5: Grade function.

Reverse Grade function: with parameters $\mathbf{c}=\mathbf{d}=+\infty$. It is described in formula (4), and shown in Figure 6 (Alonso, [no date]).

$\mu_{A}(X)=\left\{\begin{aligned} 0, & x<a \\ \frac{x-a}{b-a}, & a \leq x \leq b \\ 1, & x>b\end{aligned}\right.$

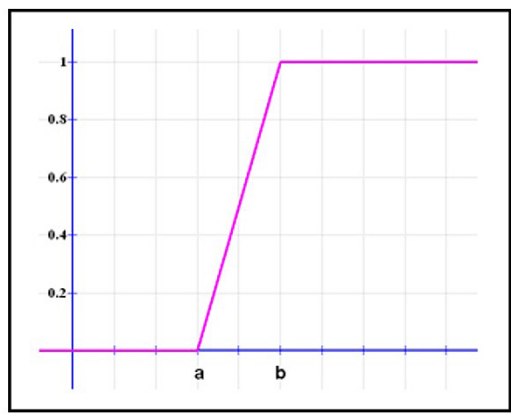

Source: Alonso, [no date]

Figure 6: Reverse Grade function. 


\section{Knowledge Base}

A system of fuzzy IF-THEN rules is considered as a knowledge-based system where inference is made on the basis of three rules of inference (Perfilieva, 2007). The 'noun' is often unimportant in the applications. Therefore, it is commonly replaced by some variable $\mathrm{X}$ whose values are not the objects themselves but only its features, such as height, volume, tension, size, abstract degrees of beauty, temperature, etc. This leads us to the concept of a fuzzy IF-THEN rule which is a kind of "abstracted" compound adjectival predication.

Definition: By fuzzy IF-THEN rule we understand either of the compound adjectival predications $\mathrm{R}^{1}$ and $\mathrm{R}^{\mathrm{A}}$ taken in the form of formulas (5) and (6), where $\mathrm{X}$ and $\mathrm{Y}$ represent features of objects (Novák and Lehmke, 2006).

$$
\begin{aligned}
& \mathcal{R}^{A}:=X \text { is } \mathcal{A} \text { AND } Y \text { is } \mathcal{B} \\
& \mathcal{R}^{1}:=I F \text { is } \mathcal{A} \text { THEN } Y \text { is } \mathcal{B}
\end{aligned}
$$

As an example, in practical implementation, such a rule can look like this:

IF it is hot, THEN ventilate a lot.

\section{Fuzzy inference}

Fuzzy inference is a method that interprets the values in the input vector and based on sets of rules, assigns values to the output vector. In fuzzy logic, the truth of any statement becomes a matter of a degree. Fuzzy inference is the process of formulating the mapping from a given input to an output using fuzzy logic. The mapping then provides a basis from which decisions can be made or patterns discerned (Kala, 2016; Kalogirou, 2014).

\section{Defuzzification}

Defuzzification is the process of obtaining a single number from the output of the aggregated fuzzy set. It is used to transfer fuzzy inference results into a crisp output. In other words, defuzzification is realized by a decision-making algorithm that selects the best crisp value based on a fuzzy set. There are several forms of defuzzification including center of gravity (COG), mean of maximum (MOM), and center average methods. The COG method returns the value of the center of area under the curve and the MOM approach can be regarded as the point where balance is obtained on a curve (Masoum and Fuchs, 2015; Patel and Champaneria, 2017).

\section{Experimental Implementation}

The aim of the experiment was to determine whether it is possible to apply the theory of fuzzy systems to ensure compliance with the principles of welfare in the environment of animal husbandry. The term "animal welfare" is being used increasingly by corporations, consumers, veterinarians, politicians, and others. However, the term can mean different things to different people. Understandably, in the past, veterinarians and farmers have seen animal welfare chiefly in terms of the body and the physical environment (shelter, feed, etc.). Meaning that if an animal is healthy and producing well, it is faring well. Research on aspects of animal welfare has also mainly focused on the body, using physiological measures, such as endorphins, plasma cortisol, and heart rate, to examine how the animal is coping with its environment. However, there are limitations to seeing animal welfare only in terms of the body. One limitation is that genetics and the environment can produce desirable physical outcomes, even though the animal's mental state is compromised. For example, a canine breed champion may have perfect conformation and be in perfect health, but it may be very anxious in its home environment. Another limitation is that some physical parameters (heart rate, plasma cortisol) are difficult to interpret, because they can be increased by both positive and negative experiences, such as the presence of a mate and the presence of a predator (Hewson, 2003; Broom, 1991; Blood and Studdert and Carling, 1988).

The main purpose of the experiment was to create a system that could better inform farmers about the needs of his animals. The air temperature was chosen for the experiment for clarity, as it is an important element of the stable microclimate. Together with other physical characteristics (air flow, relativehumidity)itmost influences the thermal state of the animal organism and its thermal wellbeing. In a certain temperature range, at constant values of other physical elements, the thermal state of the organism is considered optimal, as the animal has only a small expenditure of energy to maintain physiological functions and has a feeling of thermal well-being (comfort). This temperature range is the so-called "thermoneutral zone", which is much wider in cattle, as well as in other ruminants (such as sheep), than in monogastric animals. In addition to species affiliation, it is also affected by other factors, especially the overall level of metabolism (Doležal et al, 2004). 


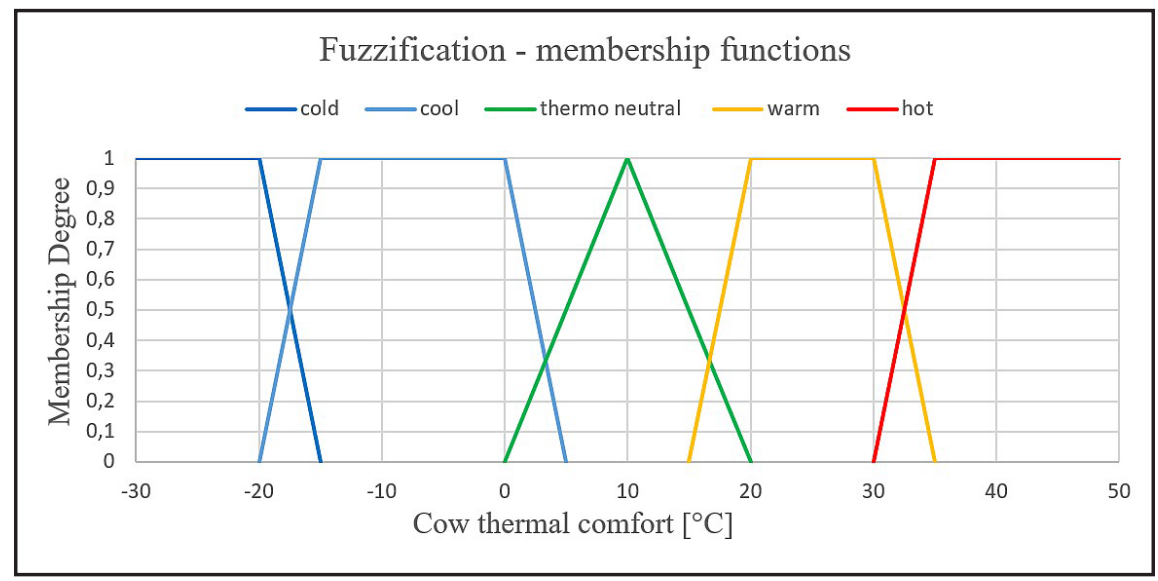

Source: own processing

Figure 7: Fuzzification - membership functions.

Based on a literature search, especially the relevant legislation, the following five fuzzy sets have been defined, which will be used for fuzzification (see Figure 7) (No. 208/2004 Coll., 2004; 98/58 / EC, 2017).

Fuzzy logic sets are implemented by the JavaScript programming language. The experiment was based on the Open Source library "es6-fuzz" (Schürmann, 2019), which was embedded into the program for the experiment. The following example program (see Figure 8) shows the creation of membership functions according to their respective graphs. The definition of the shape of individual curves is solved by including partial libraries.

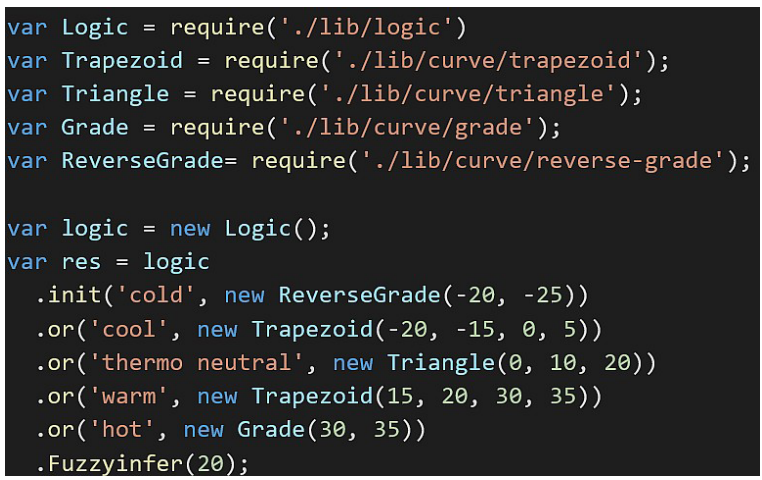

Source: own procerssing

Figure 8: Sample javascript program.

Figure 9 shows the function of the program. It is a JSON data structure, with attributes showing program variables. The office entry was at temperature of $3^{\circ} \mathrm{C}$ and $4^{\circ} \mathrm{C}$, the inference item shows with what word the program qualified the given value and "membershipDegree" constitutes the degree of belonging to the given set.

\begin{tabular}{|c|c|}
\hline msg.payload : Object & msg. payload : Object \\
\hline object & - object \\
\hline temperature: 3 & temperature: 4 \\
\hline inference: "cool" & inference: "thermo neutral" \\
\hline membershipDegree: 0.4 & membershipDegree: 0.4 \\
\hline -rules: array[5] & rules: array[5] \\
\hline$\bullet$ o: object & $\nabla:$ object \\
\hline 1: object & 1: object \\
\hline output: "cool" & output: "cool" \\
\hline Dhape: object & I shape: object \\
\hline type: "or" & type: "or" \\
\hline fuzzy: 0.4 & fuzzy: 0.19999999999999996 \\
\hline 2: object & 2: object \\
\hline output: "thermo neutral" & output: "thermo neutral" \\
\hline 'shape: object & ' shape: object \\
\hline type: "or" & type: "or" \\
\hline fuzzy: 0.3 & fuzzy: 0.4 \\
\hline 1 3: object & 13: object \\
\hline 1: object & 1 4: object \\
\hline
\end{tabular}

Source: own procerssing

Figure 9: JSON data structure.

\section{Results and discussion}

It has been verified that the fuzzy approach can be used in a very simple way to pass information to the stable staff, where it is better understood by humans in a form of a verbal expression that adds contextual information in relation to the animal.

Thanks to this approach, greater optimization of operation can be achieved, which reduces the error rate of the employees and increases the production of the stable due to compliance with welfare conditions. Fuzzy approach can therefore directly lead to an economically positive effect.

For fully automated operations, it will be necessary to use the knowledge base and subsequent defuzzification for automatic intervention, which was not the goal of this experiment. It would require specialized professionals so that the control circuit can be set optimally. 
Fuzzy control itself is a very widespread and standard tool. For example, the Japanese have been quickest to apply fuzzy logic in 1989. A fuzzy system developed by Hitachi was already used to control subway trains in the city of Sendai, accelerating and decelerating cars more smoothly than a human driver could (Pollack, 1989).

\section{Conclusion}

Apart from its usage in agriculture, utilization of fuzzy approach in conjunction with IoT can be for example aimed at developing an energysaving thermometer for measuring the temperature of the human body. The results show that HI-Thermo saves energy of monitoring significantly. Using fever body temperature measurements, the proposed system consumes $15 \%$ lower than the existing traditional monitoring of body temperature, which does not implement fuzzy logic (Mandala et al, 2017).

It would be appropriate to evaluate the benefits of the use of these technologies, similar to the work assessing the benefits of precision farming technologies in sugar beet production. (Jarolímek et al, 2019)

\section{Corresponding authors}

Ing. Vojtěch Novák

Department of Information Technologies, Faculty of Economics and Management

Czech University of Life Sciences Prague, Kamýcká 129, Prague - Suchdol, 165 00, Czech Republic

Phone: +420777714484,E-mail:novakvojtech@pef.czu.cz

\section{References}

[1] 208/2004SB (2004) "Vyhláška č. 208/2004 Sb., o minimálních standardech pro ochranu hospodářských zvírat (eAGRI)" [Online]. 2004. Available: http://eagri.cz/public/web/mze/ legislativa/pravni-predpisy-mze/tematicky-prehled/Legislativa-MZe_uplna-zneni_Vyhlaska-2004208-ochranazvirat.html [Accessed: 24 květen 2020] (In Czech).

[2] 98/58/EC (2017) "EUR-Lex - 31998L0058" - EN - EUR-Lex. [Online]. Available: https://eur-lex. europa.eu/legal-content/CS/TXT/?uri=celex:31998L0058 [Accessed: 24 May 2020].

[3] Alomar, B. and Alazzam, A. (201 "A Smart Irrigation System Using IoT and Fuzzy Logic Controller", In: ITT 2018 - Information Technology Trends: Emerging Technologies for Artificial Intelligence, Institute of Electrical and Electronics Engineers Inc. 21 Feb. 2019. pp. 175-179. ISBN 9781538671467. DOI 10.1109/CTIT.2018.8649531.

[4] Alonso, Sanjay, [no date] "eMathTeacher: Mamdani's fuzzy inference method - Membership functions" [Online]. Available: http://www.dma.fi.upm.es/recursos/aplicaciones/logica_borrosa/ web/fuzzy_inferencia/funpert_en.htm [Accessed: 24 May 2020].

[5] Altun, S. N., Dörterler, M. and Dogru, I. A. (2018) "Fuzzy Logic Based Lighting System Supported with IoT for Renewable Energy Resources", In: Proceedings - 2018 Innovations in Intelligent Systems and Applications Conference, ASYU 2018, Institute of Electrical and Electronics Engineers Inc., 29 Nov. 2018. ISBN 9781538677865.
A secondary output of this research is the finding, that fuzzy logic can be beneficial , as outlined here is the implementation communication. Alternatively, the capabilities The field of fuzzy logic still experiences very active theoretical research, so there is high possibility for new knowledge and approaches to emerge

\section{Acknowledgements}

The results and knowledge included herein from the following institutional grant. Internal grant agency of the Faculty of Economics - "Manager proces optimalization of sorghum cultivation in uncertain future climatic conditions“. use. An important opportunity for the use of fuzzy 
[6] Blood, D. C., Studdert, V. P. (1988) "Baillière's comprehensive veterinary dictionary", Baillière Tindall. ISBN 0702011959.

[7] Broom, D. M. ( 1991) "Animal welfare: concepts and measurement", $2^{\text {nd }}$ Journal of Animal Science. Vol. 69, No. 10, p. 4167-4175. E-ISSN 1525-3163. DOI 10.2527/1991.69104167x.

[8] Chan, Ch. O., LAU, H. C. W. and FAN, Y. (2018) "IoT data acquisition in fashion retail application: Fuzzy logic approach", In: 2018 International Conference on Artificial Intelligence and Big Data, ICAIBD 2018, Institute of Electrical and Electronics Engineers Inc. 25 June 2018, pp. 52-56. ISBN 9781538669877. DOI 10.1109/ICAIBD.2018.8396166.

[9] Doležal, O., Bílek, M., Dolejš, J. (2004) "Zásady welfare a nové standardy EU v chovu skotu", Resarch Institute of Animal Production. ISBN 8086454517. (In Czech).

[10] Fayaz, M. nd Kim, D. (2017) "Actuator Control Based on Fuzzy Logic For Intilligent Iot Based Service Composition", $19^{\text {th }}$ International Journal of Soft Computing and Artificial Intelligence [Online]. Vol. 5, No. 1. ISSN 2321-404X.

[11] Jarolímek, J., Masner, J., Vaněk, J. and Pánková, L. (2019) “Assessing benefits of precision farming technologies in sugar beet production", Listy Cukrovarnicke a Reparske, Vol. 135, No. 2, pp. 57-63. ISSN 12103306.

[12] Hewson, C. J. (2003) "What is animal welfare? Common definitions and their practical consequences", The Canadian veterinary journal $=$ La revue veterinaire canadienne, Vol. 44, No. 6, p. 496-499. [Online]. Available: http://www.ncbi.nlm.nih.gov/pubmed/12839246 [Accessed: 25 May 2020].

[13] Kala, R. (2016) "Fuzzy-Based Planning", In: On-Road Intelligent Vehicles. Motion Planning for Intelligent Transportation Systems, pp. 279-317. ISBN 978-0-12-803729-4. DOI 10.1016/b978-0-12-803729-4.00010-6.

[14] Kalogirou, S. A. (2014) " Chapter 11 - Designing and Modeling Solar Energy Systems", In: Solar Energy Engineering", pp. 583-699. ISBN 978-0-12-397270-5. DOI 10.1016/b978-0-12-397270-5.00011-x.

[15] Mandala, S., Novian, A., S., Syahrul, M. M. and Shamila (2017) "Energy efficient IoT thermometer based on fuzzy logic for fever monitoring", In: $20175^{\text {th }}$ International Conference on Information and Communication Technology, ICoIC7 2017, Institute of Electrical and Electronics Engineers Inc. ISBN 9781509049127. DOI 10.1109/ICoICT.2017.8074640.

[16] Masoum, M. A. S. and Fuchs, E. F. (2015) "Optimal Placement and Sizing of Shunt Capacitor Banks in the Presence of Harmonics", Power Quality in Power Systems and Electrical Machines [Online]. pp. 887-959. Available: https://linkinghub.elsevier.com/retrieve/pii/B9780128007822000105 [Accessed: 23 May 2020]. DOI 10.1016/b978-0-12-800782-2.00010-5.

[17] Novák, V. and Lemke, S. (2006) "Logical structure of fuzzy IF-THEN rules", Fuzzy Sets and Systems. Vol. 157, No. 15, pp. 2003-2029. ISSN 0165-0114. DOI 10.1016/j.fss.2006.02.011.

[18] Patel, A. and Champanera, T. A. (2017) "Fuzzy logic based algorithm for Context Awareness in IoT for Smart home environment", In: IEEE Region 10 Annual International Conference, Proceedings/ TENCON, Institute of Electrical and Electronics Engineers Inc., 8 Feb. 2017, pp. 1057-1060. ISBN 9781509025961. DOI 10.1109/TENCON.2016.7848168.

[19] Perfilieva, I. (2007) "Analytical theory of fuzzy IF-THEN rules with compositional rule of inference", In: Wang P.P., Ruan D., Kerre E.E. (eds) Fuzzy Logic. Studies in Fuzziness and Soft Computing, Vol. 215, Springer, Berlin, Heidelberg pp. 174-191. E-ISBN 978-3-540-71258-9, ISBN 978-3-540-71257-2. DOI 10.1007/978-3-540-71258-9_9.

[20] Pollack, A. (1989) "Fuzzy Computer Theory: How to Mimic the Mind? - The New York Times", The New York Times Archives [Online]. Available: https://www.nytimes.com/1989/04/02/us/fuzzycomputer-theory-how-to-mimic-the-mind.html [Accessed 25 květen 2020].

[21] Rezaee, M. R., Kadkhodaie-Ilkhchi, A. and Alizadeh, P. M. (2008) "Intelligent approaches for the synthesis of petrophysical logs", Journal of Geophysics and Engineering, Vol. 5, No. 1, pp. 12-26. E-ISSN 1742-2140, ISSN 1742-2132. DOI 10.1088/1742-2132/5/1/002. 
[22] Ross, T. J. (2004) "Fuzzy logic with engineering applications", John Wiley. ISBN 9780470860748.

[23] Rymarczyk, J. (2020) "Technologies, Opportunities and Challenges of the Industrial Revolution 4.0: Theoretical Considerations", Entrepreneurial Business and Economics Review, Vol. 8, No. 1, pp. 185-198. E-ISSN 2353-8821, ISSN 2353-883X. DOI 10.15678/EBER.2020.080110.

[24] Schürmann, S. (2019) "es6-fuzz - npm" [Online]. Available: https://www.npmjs.com/package/es6fuzz [Accessed: 24 May 2020].

[25] Stočes, M., Vaněk, J., Masner, J. and Pavlík, J. (2016) "Internet of things (IoT) in agriculture - Selected aspects", Agris On-line Papers in Economics and Informatics, Vol. 8, No. 1, pp. 83-88. ISSN 1804-1930. DOI 10.7160/aol.2016.080108.

[26] Wang, K. (2001) "Computational Intelligence in Agile Manufacturing Engineering, In: Agile Manufacturing: The 21 st Century Competitive Strategy, pp. 297-315. ISBN 978-0-08-043567-1. DOI 10.1016/B978-008043567-1/50016-4.

[27] Xu, B. (2010) "Grading of cotton by color measurement", In: Colour Measurement: Principles, Advances and Industrial Applications. Elsevier Ltd., p. 253-278. ISBN 9781845695590. DOI 10.1533/9780857090195.2.253.

[28] Zadeh, L. A. (1996) "Fuzzy logic = computing with words", IEEE Transactions on Fuzzy Systems, Vol. 4, No. 2, p. 103-111. ISSN 1063-6706. DOI 10.1109/91.493904. 